\title{
Myocardial infarction in familial hyper-alpha and hypo-beta-lipoproteinaemia
}

\author{
SimON W. RABKIN* \\ M.D., F.R.C.P.(C), F.A.C.C. \\ RODNEY LEDWICH \\ M.D., F.R.C.P.(C), F.A.C.C. \\ DAVID MYMIN \\ M.D. \\ Department of Medicine, Section of Cardiology, University of Manitoba, Winnipeg, Manitoba
}

\begin{abstract}
Summary
This is the documentation of an acute myocardial infarction in a 45-year-old woman with familial hyper- $\alpha$ - and hypo- $\beta$-lipoproteinaemia. This dyslipoproteinaemia has been rarely associated with clinical evidence of ischaemic heart disease. Documentation of angiographically normal coronary arteries in this patient is consistent with the concept that increased $\alpha$-lipoprotein (HDL) and low $\beta$-lipoprotein (LDL) may prevent atherosclerosis. Thus, myocardial infarction in patients with this dys-lipoproteinaemia should be attributable to factors other than coronary atherosclerosis.
\end{abstract}

\section{Introduction}

The relationship between serum cholesterol and atherosclerosis is a function of the distribution of cholesterol between the different lipoproteins. Atherosclerosis and premature cardiovascular disease are associated with increased levels of low density lipoprotein cholesterol (LDL-C, or $\beta$-lipoprotein cholesterol), triglycerides and very low density lipoprotein cholesterol and decreased levels of high density lipoprotein (HDL-C or $\alpha$-lipoprotein cholesterol) (Gofman et al., 1950; Miller and Miller, 1975; Castelli et al., 1977a; Rhoades, Gulbrandsen and Kagan, 1976; Gordon et al., 1977; Goldbourt and Medalie, 1979). Miller and Miller (1975) proposed that HDL is involved in the clearance of cholesterol from the arterial wall so that reduced levels of HDL-C accelerate the development of atherosclerosis. The converse of this appears to be also substantiated. Increased levels of HDL-C have been found in families characterized by longevity. Glueck et al. $(1975,1976,1977)$ reported significantly increased longevity in 18 kindreds with familial hyper- $\alpha$-lipoproteinaemia as well as an increased

* Address for reprints: Dr S. W. Rabkin, Department of Medicine, Shaughnessy Hospital, Vancouver, BC, V6H 3NI. proportion of families with this lipoprotein pattern amongst octogenarian kindred. In kindred with hyper- $\alpha$-lipoproteinaemia, myocardial infarction was an extremely rare event, and occurred only in older age-groups. These studies required a retrospective examination for coronary artery disease amongst family members and relied sometimes only on death certificate data to confirm a diagnosis of myocardial infarction. A patient is now reported who had familial hyper- $\alpha$-lipoproteinaemia and documented evidence of myocardial infarction at a young age, and who had no evidence of coronary atherosclerosis at coronary angiography.

\section{Case summary}

A 48-year-old woman had been admitted to hospital 4 years earlier with acute non-transmural myocardial infarction. The evidence for this diagnosis was the sudden onset of burning central chest pain, radiating to the left arm starting when the patient was at rest, and persisting for approximately $18 \mathrm{hr}$, associated with diaphoresis. Electrocardiograms showed serial ST segment and $T$ wave changes but no $Q$ waves (Fig. 1). Serial measurements of enzymes showed a rise and fall in creatine kinase, aminoaspartate transaminase and lactic dehydrogenase with peak values respectively 2,4 and 2 times the upper limit of normal.

Several months later, because of recurrent chest discomfort, she underwent cardiac catheterization and coronary angiography. This showed a left ventricle of normal size and contractility (end diastolic volume of $98 \mathrm{ml}$, end systolic volume of $26 \mathrm{ml}$ and ejection fraction of $74 \%$ ). Selective coronary angiography showed a normal anatomic pattern, normal vessel calibre throughout and no evidence of obstruction (Fig. 2). Myocardial lactate extraction ratio was $3 \%$ at rest with no significant change with rapid atrial pacing $(38.7 \%)$. Fasting blood sugar was $102 \mathrm{mg} / \mathrm{dl}$. 


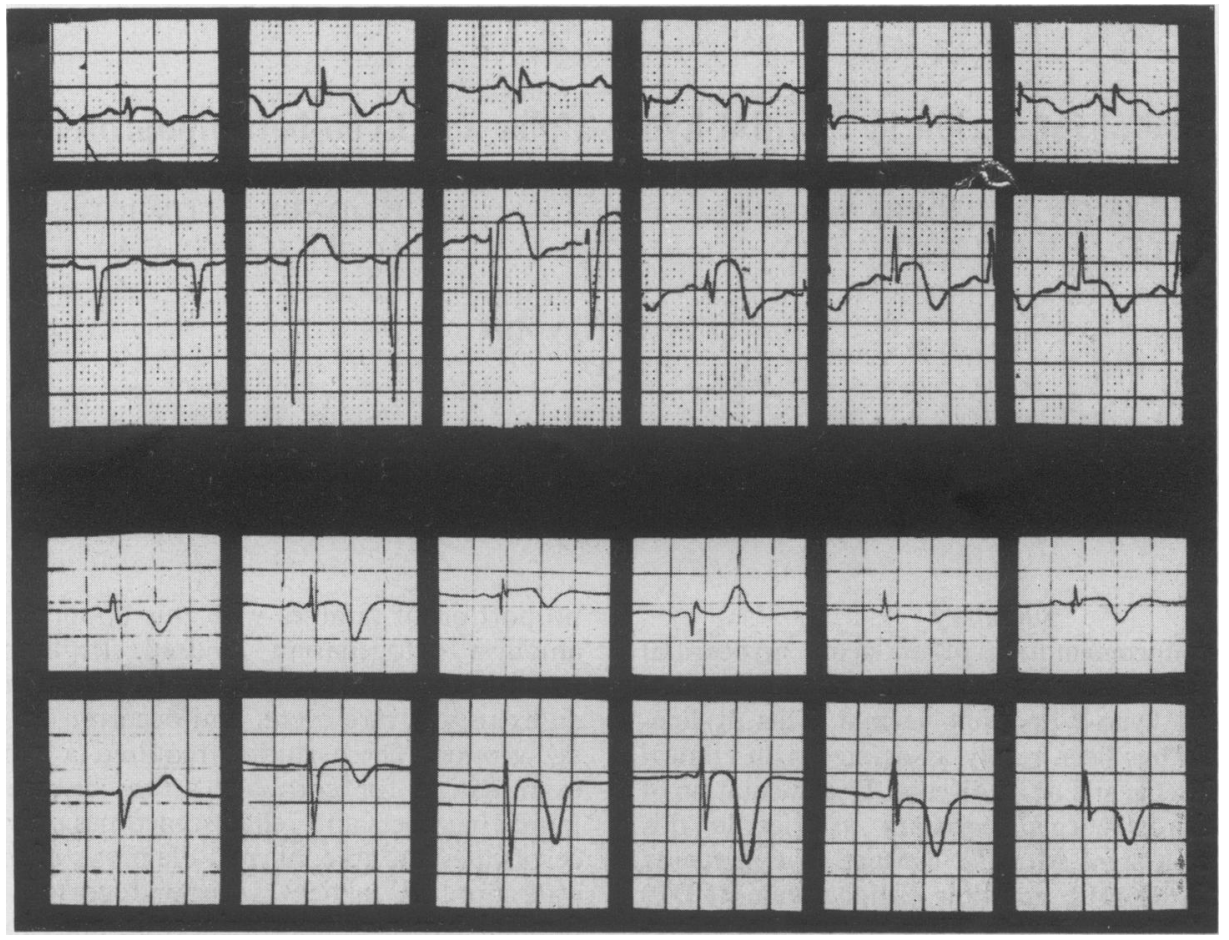

FIG. 1. Serial electrocardiograms showing ST segment and $T$ wave changes but no $Q$ waves.

She was referred for investigation of lipoproteins after starting an exercise rehabilitation programme. Lipoprotein electrophoresis at the time of cardiac catheterization had shown a prominent $\alpha$ peak of $67.6 \%$. She had formerly smoked cigarettes and had stopped 15 years earlier. She had been taking birth control pills for 8 years and had stopped one year before the myocardial infarction. She was experiencing menopause as evidenced by irregular periods. She was not obese (height $160 \mathrm{~cm}$, weight $54 \mathrm{~kg}$ ) and her alcohol consumption was not more than 6 ounces of wine per week. There was no history of diabetes mellitus or thyroid disorders but was once told that she had borderline hypertension.

\section{Family history}

This revealed that her mother died at the age of 73 years of cancer; her father was alive, aged 86 years, vigorous, active and occasionally consumed alcohol (2-3 times per week). The only family history of heart disease was in one paternal uncle who was obese and died in his 40 s of postoperative myocardial infarction. The other 5 uncles lived into their $70 \mathrm{~s}$. The patient had no brothers or sisters but had 4 daughters. All daughters except the youngest were menstruating, they were non-smokers, infrequently consumed alcohol and only the second eldest was on birth control pills.

\section{Lipoprotein analysis}

After a 14-hr overnight fast, blood samples were obtained into tubes containing disodium ethylene diaminetriacetate and used for determination of cholesterol and triglycerides by enzymatic methods (Allain et al., 1974; Sampson, Demers and Krieg, 1975). HDL-C was assayed by the same methodology after manganese-heparin precipitation (Warnick and Albers, 1978). The Beckman lipoprotein Profiling System was used (Beckman Co., Palo Alto, California).

Lipoprotein analysis revealed low concentration of LDL-C, triglycerides and increased concentrations of HDL-C that exceeded LDL-C in the patient and all but one family member (Table 1).

\section{Discussion}

The diagnostic criteria for familial hyper- $\alpha$-lipoproteinaemia of Glueck et al. $(1975,1976,1977)$ are as follows: (1) HDL-C at or greater than the upper normal limit of $70 \mathrm{mg} / \mathrm{dl}$; (2) detection of a similar pattern in a first degree relative; (3) absence of conditions to which hyper-alpha-lipoproteinaemia 

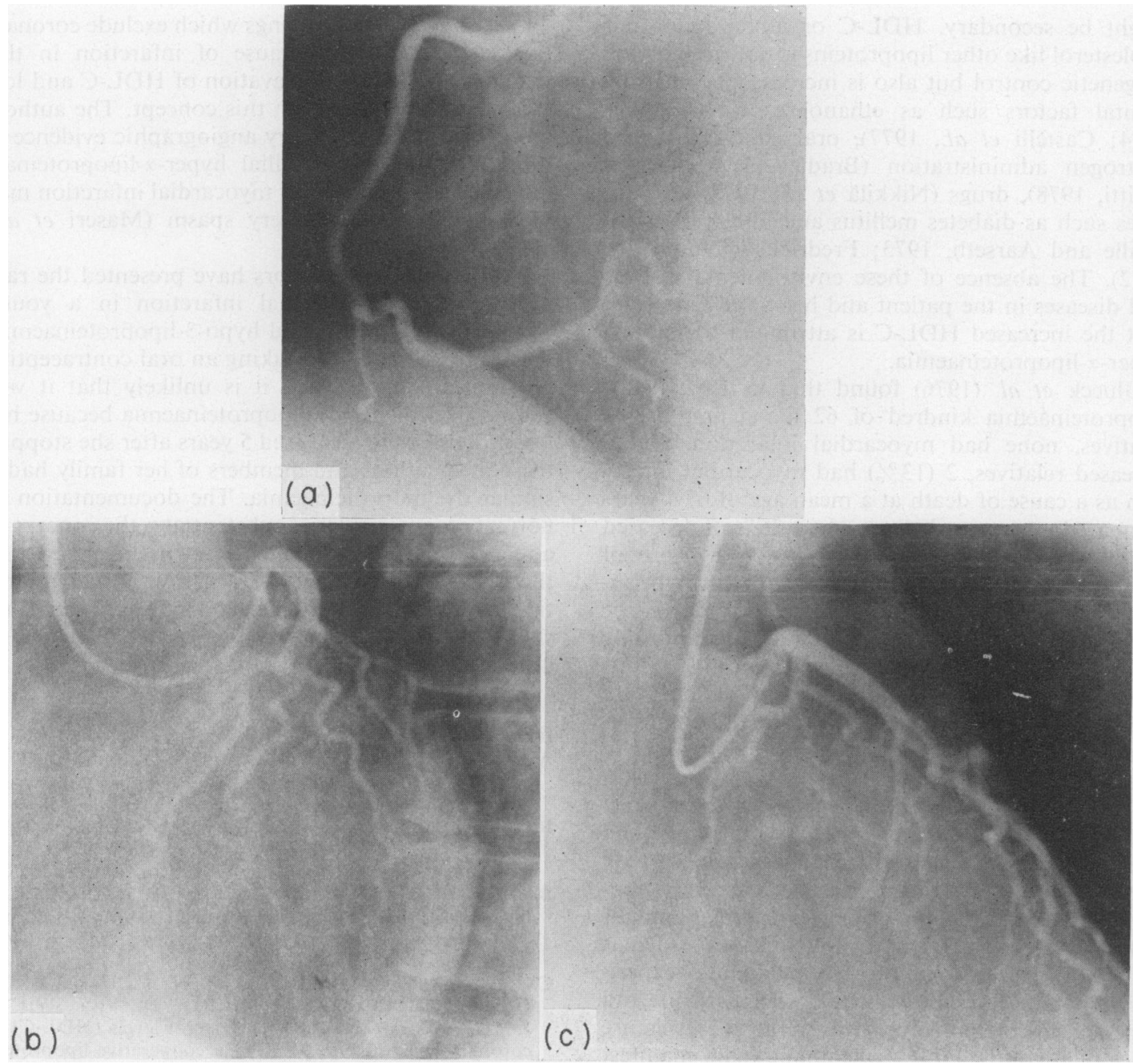

Fig. 2. Selective coronary angiography showing (a) a normal anatomic pattern, (b) normal vessel calibre throughout and (c) no evidence of obstruction.

TABLE 1. Lipoproteins in propositus and first-degree family relatives

\begin{tabular}{lccccc}
\hline & $\begin{array}{c}\text { Age } \\
\text { (years) }\end{array}$ & $\begin{array}{c}\text { Total cholesterol } \\
(\mathrm{mg} / \mathrm{dl})\end{array}$ & $\begin{array}{c}\text { LDL-C } \\
(\mathrm{mg} / \mathrm{dl})\end{array}$ & $\begin{array}{c}\text { HDL-C } \\
(\mathrm{mg} / \mathrm{dl})\end{array}$ & $\begin{array}{c}\text { Triglycerides } \\
(\mathrm{mg} / \mathrm{dl})\end{array}$ \\
\cline { 2 - 6 } & \multicolumn{2}{c}{\begin{tabular}{c}
\multicolumn{2}{c}{ 'Normal Range' } \\
for age group
\end{tabular}} & \multicolumn{2}{c}{$\begin{array}{c}\text { 'Normal Range' } \\
\text { for age/sex }\end{array}$} \\
\hline Father & \multicolumn{2}{c}{$107\left(160-330^{*}\right)$} & $25(80-210)$ & $70(30-65)$ & $30(10-190)$ \\
Propositus & 86 & $167(150-310)$ & $46(80-190)$ & $113(40-95)$ & $58(10-160)$ \\
Daughters & 48 & $133(120-240)$ & $42(60-170)$ & $69(35-75)$ & $62(10-140)$ \\
& 25 & $129(120-240)$ & $56(60-170)$ & $81(35-75)$ & $50(10-140)$ \\
& 14 & $121(120-230)$ & $66(50-170)$ & $59(30-70)$ & $42(10-140)$ \\
& 13 & $138(120-230)$ & $19(50-170)$ & $87(30-70)$ & $34(10-140)$ \\
\hline
\end{tabular}

* No satisfactory normals in the authors' laboratory for 80-year-old patients. Values are from 50 to 59 years age group. 
might be secondary. HDL-C or alpha-lipoprotein cholesterol like other lipoproteins is not only subject to genetic control but also is increased by environmental factors such as ethanol excess (Mishkel, 1974; Castelli et al., 1977), oral contraceptive or oestrogen administration (Bradley, Wingerd and Petitti, 1978), drugs (Nikkilä et al., 1978) and diseases such as diabetes mellitus and biliary cirrhosis (Wille and Aarseth, 1973; Fredrickson and Levy, 1972). The absence of these environmental factors and diseases in the patient and her family indicates that the increased HDL-C is attributed to familial hyper- $\alpha$-lipoproteinaemia.

Glueck et al. (1976) found that in 18 hyper- $\alpha-$ lipoproteinaemia kindred of 62 living first degree relatives, none had myocardial infarction. Of 15 deceased relatives, $2(13 \%)$ had myocardial infarction as a cause of death at a mean age of 63.5 years compared to a control group where $36 \%$ of deceased relatives had myocardial infarction as a cause of death. Also, in octogenarian kindred with hyper- $\alpha-$ or hypo- $\beta$-lipoproteinaemia none of 67 first degree living relatives had myocardial infarction and only $2 \%$ of deceased relatives had myocardial infarction as a cause of death. Thus, the present patient with familial hyper- $\alpha$-lipoproteinaemia who had a myocardial infarction at the age of $\mathbf{4 3}$ years represents an extremely unusual entity.

The epidemiological evidence of a reduced incidence of premature cardiovascular morbidity and mortality from atherosclerosis associated with increased levels of HDL-C has been recently supported by experimental evidence. Firstly, animals with high levels of HDL-C relative to LDL-C such as the dog or cat seldom manifest spontaneous or experimentally induced atherosclerosis, whereas swine and some species of monkeys whose HDL-C levels are lower relative to LDL-C, resembling man, manifest spontaneous atherosclerosis and vascular lesions that can be experimentally induced (Howard, 1974). Secondly, HDL-C in serum correlates inversely with the degree of arterial tissue cholesterol content (Bondjers et al., 1976). Thirdly, HDL can produce a net removal of cellular cholesterol from a variety of cells in culture including arterial smooth muscle (Stein et al., 1975). Thus, the concept has developed that HDL serves the physiological role of clearing excess cellular cholesterol from peripheral tissues, thus minimizing the cholesterol content in arteries and retarding the atherosclerotic process.

Plasma HDL-C has an inverse relationship to plasma LDL-C both in population studies (Miller and Miller, 1975) and in families with increased longevity (Glueck et al., 1976). Thus plasma HDL-C correlates negatively and plasma LDL-C correlates positively with development of atherosclerosis (Miller and Miller, 1975; Gofman et al., 1950).
The angiographic findings which exclude coronary atherosclerosis as the cause of infarction in this patient with a marked elevation of HDL-C and low LDL-C is consistent with this concept. The authors are not aware of coronary angiographic evidence in other persons with familial hyper- $\alpha$-lipoproteinaemia. The aetiology of her myocardial infarction may have been coronary artery spasm (Maseri et al., 1979).

In summary, the authors have presented the rare occurrence of myocardial infarction in a young woman with hyper- $\alpha$ - and hypo- $\beta$-lipoproteinaemia. Although she had been taking an oral contraceptive preparation for 8 years, it is unlikely that it was responsible for her dyslipoproteinaemia because her lipoproteins were measured 5 years after she stopped these medications and members of her family had a similar dyslipoproteinaemia. The documentation of normal coronary arteries substantiates the concept of a reduced aeherosclerotic tendency in the presence of this dyslipoproteinaemia. Thus, myocardial infarction in familial hyper- $\alpha$-and hypo- $\beta$-lipoproteinaemia should be attributed to factors other than coronary atherosclerosis.

\section{References}

Allain, C.C., Poon, L.S., Chan, C.S.G., Richmond, W. \& FU, P.C. (1974) Enzymatic determination of total serum cholesterol. Clinical Chemistry, 20, 470.

Bondjers, G., Gustafson, A., Kral, J., Scherstén, T. \& SJóströ̀, L. (1976) Cholesterol content in arterial tissue in relation to serum lipoproteins in man. Artery, 2, 200.

Bradley, D.D., Wingerd, J. \& Petitti, D.B. (1978).Serum high density lipoprotein cholesterol in women using oral contraceptives, estrogens and progestins. New England Journal of Medicine, 229, 17.

Castelli, W.P., Doyle, J.T., Gordon, T., Hames, C.G., Hulley, S.B., KagaN, A., McGell, D., Vick, W.J. \& ZUKEL, W.J. (1977a) HDL cholesterol levels (HDL-C) in coronary heart disease (CHD) - a cooperative lipoprotein phenotyping study. Circulation, 55, 767.

Castelli, W.P., Doyle, J.T., Gordon, T., Hames, C.G., Huortland, M.C., Hulley, S.B., Kagan, A. \& Zukel, W. (1977b) Alcohol and blood lipids. Lancet, ii, 153.

Frederickson, D.S. \& Levy, R.I. (1972) Familial hyperlipoproteinemias, In: The Metabolic Basis of Inherited Disease, 3rd edn (Ed by Stanbury, J. B., Syngaarden, J. B. \& Fredrickson, D. S.), p. 545. McGraw Hill, New York.

Glueck, C.J., Fallot, R.W., Millett, F., Gartside, P., ELSTON, R.C. \& Go, R.C.P. (1975) Familial hyper-alphalipoproteinemia; studies in eighteen kindred. Metabolism, 24, 1243.

Glueck, C.J., Gartside, P., Fallot, R.W., Sielski, J. \& STEINER, P.M. (1976) Longevity syndromes: familial hypobeta and familial hyperalpha lipoproteinemia. Journal of Laboratory and Clinical Medicine, 8, 941.

Glueck, C.J., Gartside, P.S., Steiner, P.M., Miller, M., Todhientex, T., Hoaf, J., Pueke, H., Terrana, M., FAllot, R.W. \& KoshYAP, M.L. (1977) Hyperalpha- and hypobeta-lipoproteinemia in octogenarian kindreds. Atherosclerosis, 27, 387.

GofMAN, J.W., JoNes, H.B., Lindgren, F.T., Lyon, T.P., Elliot, H.A. \& Strowser, B. (1950) Blood lipids and human atherosclerosis. Circulation, 2, 161. 
Goldbourt, U. \& Medalie, J.H. (1979) High density lipoprotein cholesterol and incidence of coronary heart disease. The Israel IHD Study. American Journal of Epidemiology, 109, 296.

Gordon, T., Castelli, W.P., Huortland, M.C., Kannel, W.P. \& DAWBER, T.R. (1977) High density lipoprotein as a protective factor against coronary heart disease. American Journal of Medicine, 62, 707.

HowARD, A.N. (1974) Animal model of atherosclerosis and/or myocardial infarction. In: Atherosclerosis III (Ed by Schettler, G. \& Weizel, A.), p. 308. Springer Verlag, New York.

Maseri, A., L'Abbate, A., Chierchia, S., Parodi, O., Severi, S., Biagimi, A., Manzilli, M. \& Ballestra, A.M. (1979) Significance of spasm in the pathogenesis of ischemic heart disease. American Journal of Cardiology, 44, 789.

Miller, G.J. \& Miller, N.E. (1975) Plasma high density lipoprotein concentration and development of ischaemic heart disease. Lancet, i, 16.

Mishrel, M.A. (1974) Alcohol and alphalipoprotein cholesterol. Annals of Internal Medicine, 81, 564.
Nikkilä, E.A., Kaste, M., Ehnholm, C. \& Vilkari, J. (1978) Increase of serum high density lipoprotein in phenytoin users. British Medical Journal, 11, 99.

Rhoades, G.G., Gulbrandsen, C.L. \& Kagan, A. (1976) Serum lipoproteins and coronary heart disease in a population survey of Hawaii-Japanese men. New England Journal of Medicine, 294, 293.

Sampson, E.J., Demers, L.M. \& KRIEg, A.F. (1975) Faster enzymatic procedure for serum triglycerides. Clinical Chemistry, 21, 1983.

Stein, Y., Glongeaud, M.C., Fainaru, M. \& Stein, O. (1975) The removal of cholesterol from aortic smooth muscle cells in culture and Landschultz ascites cells by fractions of human high density apolipoprotein. Biochimica et biophysica acta, 380, 106.

WARNICK, G.R. \& Albers, J.J. (1978) A comprehensive evaluation of the heparin-manganese precipitation procedure for estimating high density lipoprotein cholesterol. Journal of Lipid Research, 19, 65.

Wille, L.L. \& AARSETH, S. (1973) Demonstration of hyperalpha-lipoproteinemia in three diabetic patients. Clinical Genetics, 4, 281. 